\title{
Anti-Diabetic Activity of Methanolic Extract of Momordica Balsamina in Rabbits
}

\author{
AMINATU ABUBAKAR SANI ${ }^{1}$, SHERIFAT BANKE IDRIS ${ }^{1}$, SAIDU YAKUBU ${ }^{1}$ \\ 1.Department of Veterinary Pharmacology and Toxicology, Faculty of Veterinary Medicine, \\ Usmanu Danfodiyo University Sokoto, PMB 2346, Sokoto Nigeria. \\ *Corresponding author: Email: abbavet2008@yahoo.com \\ Phone: +2348036432215 \\ DOI: 10.31364/SCIRJ/v7.i6.2019.P0619657 \\ http://dx.doi.org/10.31364/SCIRJ/v7.i6.2019.P0619657
}

\begin{abstract}
Antidiabetic property of methanolic extract of Momordica balsamina, was evaluated in alloxan induced diabetic rabbits. Sixteen adult rabbits divided into four groups of four animals each were used for this study. Diabetes was induced by a single intravenous injection of alloxan monohydrate $(150 \mathrm{mg} / \mathrm{kg})$ in groups A, B and C. Group D served as negative control. Following induction of diabetes, group A and group B were treated with $200 \mathrm{mg} / \mathrm{kg}$ and 250mg/kg body weight of the extract of Momordica balsamina, respectively while group $\mathrm{C}$ was treated with glibenclamide (positive control). The results showed that administration of Momordica balsamina extract at $200 \mathrm{mg} / \mathrm{kg}$ and $250 \mathrm{mg} / \mathrm{kg}$ body weight significantly $(\mathrm{P}<0.05)$ reduce the blood sugar after 24 hours of treatment. Furthermore, there was no significant difference between blood glucose levels of Momordica balsamina extract and glibenclamide treated rabbits. The data from this study suggests that Momordica balsamina extract in rabbits reduces blood sugar and can be comparable to the effects of glibenclamide.
\end{abstract}

Keywords: Alloxan, glibenclamide, Hypoglycemia, Momordica balsamina, Rabbits,

\section{INTRODUCTION}

Diabetes mellitus is characterized by high levels of glucose because of a deficiency in insulin (Ponnusamy et al., 2011). High level glucose or hyperglycemia, is a common characteristic of both type 1 diabetes mellitus (T1DM) and type 2 diabetes mellitus (T2DM), and the disease has the potential to cause serious complications due to its chronic nature (Konstantinos et al., 2015). Dibetes mellitus is an emerging global epidemic, with high global morbidity andmortality (Konstantinos et al., 2015).Treatments for diabetes mellitus include sulfonylureas, biguanides, meglitinides, and insulin many of which have a number of adverse effects hence the need to search for safer hypoglycemics (Saxena and Vikram, 2004).However these orthodox treatment options have alot of adverse effects hence the search for new and safer alternatives is important (Saxena and Vikram 2004).Here in Africa this phenomenon is no less important alongside limited access to conventionally approved drugs due to socioeconomic reasons. Yet we are aware the continent is endowed with its own share of rich medicinal plants. Another problem exists in that multiple studies have shown that there is a lack of proper adherence to antidiabetic drugs (Morgan 2017).

Traditional medicines are used all over the world for the management of diabetes and Momordica balsamina is one of such plant that has shown antidiabetic effects in rats (Faujdar et al., 2012). Momordica balsamina is a plant commonly known as African pumpkin (or African cucumber), Balsam apple (Balsam pear or Bitter melon) in English and Garahuni in Hausa. The leaves, fruit, seeds, and bark of this plant have been reported to have various medicinal and nutritional values (Hassan and Umar, 2006; Bot et al., 2007; Benoit-Vical et al., 2006; Matawalli et al., 2004; Tommasi et al., 1995; karumi et al., 2003). Studies have also revealed the hypoglycaemic effects of the leaves and fruits in rabbits (Karumi and Bobboi, 1999; Karumi et al., 1999). Phytochemical 
screening of M. balsamina revealed the presence of tannins, saponins and lectins (Akinniyi et al., 1983). Hassan et al., 2006 reported the leaves to be an important source of 17 amino acids (isoleucine, leucine, lysine, methionine, cysteine, phenylalanine, tyrosine, threonine, valine, alanine, arginine, aspartic acid, glutamic acid, glycine, histidine, proline and serine. The plant extract reduced blood glucose level in alloxan induced rabbit at $1000 \mathrm{mg} / \mathrm{kg}$ comparable to that of chlopropamide (Otimenyin and Uguru, 2005).In our experiment we observed the blood glucose lowering effects of lower doses from previous studies. M. Balsamina was sourced from a semi arid region of Nigeria in this study.We observed whether the environmental factors and climate will affect the known hypoglycaemic activity of the plant. Studies have shown plants secondary metabolites contents which are responsible for their medicinal value, vary according to the environmental conditions in which they are grown (Dong et al., 2011).

\section{MATERIALS AND METHODS}

Momordica balsamina (stem, roots, leaves and seeds) used in this study were sampled and collected at Nasarawa village of Jega Local Government area, Kebbi State, Nigeria. Fresh plant specimen was deposited for identification and authentication at the Herbarium Unit in the Department of Biological Sciences, Usmanu Danfodiyo University, Sokoto. The plant (stem, leaves, roots and seeds) were dried at room temperature under shade until a constant weight was achieved. After air drying at room temperature, the dried material was then powdered using pestle and mortar. The powdered whole plant was extracted with $80 \%$ methanol using Soxhlet apparatus and then the residues were further extracted with dichloromethane separately as described by Sasidharan et al. 2011.

\section{Acute Oral Toxicity Study}

Five Rabbits (California white) were purchased from Dan Kure market, Sokoto, Sokoto State. They were kept in a standard laboratory animal pen of Veterinary Teaching Hospital, Usmanu Danfodiyo University, Sokoto. The rabbits were allowed to acclimatize for a period of 2 weeks during which clean water, wheat bran and vegetables were provided to them ad libitum During the acclimatization, the temperature and weight of the rabbits were taken every day to ensure they were fit and healthy for the experiment.

The limit dose test for acute oral toxicity testing of chemicals was used (OECD, 2006) using five rabbits. A 3000mg/kg dose of the extract (Momordica balsamina) was used as the starting dose and 10mls of distilled water was used as a vehicle for oral use. The first animal was dosed and observed for 48 hours for any behavioural change due to toxicity and possibly death. Observed toxicity signs mean the next animal will receive a lower dose. If the animal survived the procedure was repeated with same dose of $3000 \mathrm{mg} / \mathrm{kg}$ of the extract on the next rabbit thus every $48 \mathrm{hrs}$ another rabbit was dosed if the former survives. The $\mathrm{LD}_{50} \mathrm{of}_{\mathrm{f}}$ plant extract of Momordica balsamina was determined from the result of the acute oral toxicity test.

\section{Diabetic Study}

Overnight fasted animals were divided randomly into groups of 4 animals per group. Group A, B and C were all induced with diabetes and Group D was used as negative control Diabetes mellitus was induced by a single intravenous injection of alloxan monohydrate $(150 \mathrm{mg} / \mathrm{kg})$ dissolved in $3 \mathrm{ml}$ of distilled water through the marginal ear vein as described by Etuk, (2010).The control group did not receive any treatment. To reduce death due to hypoglycemic shock, alloxan treated rabbits received $5 \%$ of glucose instead of water for $24 \mathrm{hr}$ after diabetes induction. Sugar levels were monitored to confirm hyperglycemia. and once it was established the extract doses and glibenclamide were administered. The effects were observed and blood glucose measured using a glucometer (Accu-Check, USA). Measurements were taken after 4 hours then every 24 hours for 3 days after induction of diabetes with alloxan, the rabbits glucose levels were monitored and blood sugar level of more than $180 \mathrm{mg} / \mathrm{dl}$ were taken as moderate diabetes (Etuk, 2010). 


\section{RESULTS}

All animals survived the limit dose test of $3000 \mathrm{mg} / \mathrm{kg}$ body weight. Therefore, the $\mathrm{LD}_{50}$ of the methanolic extract was assumed to be more than $3000 \mathrm{mg} / \mathrm{kg}$ body weight according to the guidelines of OECD, 2006. The extract showed anti-diabetic activity with maximum effect seen at 4 hours and 24 hours of diabetic induction between groups A and D, also C and D at $\mathrm{p}<0.05$. Significant changes were also observed at 24 hours after the first treatment between group B and D, so also group C and D as shown in Table I and Figure 1.The effect of the extract treated groups (A and B) and glibenclamide treated group (C) were more pronounced at 4 and 24 hours post treatment. However, the group that received $200 \mathrm{mg} / \mathrm{kg}$ body weight showed a steady decline in the sugar level compared to both the group that received $250 \mathrm{mg} / \mathrm{kg}$ and the positive control group.

Table 1: Random blood sugar levels of 16 rabbits before and after treatment

\begin{tabular}{|l|l|l|l|l|l|}
\hline Group & $\begin{array}{l}\text { Glucose level } \\
(\mathrm{mg} / \mathrm{dl})\end{array}$ & $\begin{array}{l}\text { After 4hrs } \\
\text { Intervention }\end{array}$ & $\begin{array}{l}\text { After 24hrs } \\
\text { Intervention }\end{array}$ & $\begin{array}{l}\text { After 48hrs } \\
\text { intervention }\end{array}$ & $\begin{array}{l}\text { After72hrs } \\
\text { Intervention }\end{array}$ \\
\hline $\mathrm{A}(200 \mathrm{mg} / \mathrm{kg})$ & $205.0 \pm 12.1^{\mathrm{a}}$ & $196.0 \pm 12.1^{\mathrm{a}}$ & $166.0 \pm 11.7$ & $147.0 \pm 11.2$ & $135.8 \pm 7.6$ \\
\hline $\mathrm{B}(250 \mathrm{mg} / \mathrm{kg})$ & $172.5 \pm 18.9$ & $186.5 \pm 10.4^{\mathrm{b}}$ & $171.8 \pm 11.7^{\mathrm{a}}$ & $154.5 \pm 14.6$ & $121.8 \pm 2.8$ \\
\hline $\mathrm{C}($ glibenclamide0.23mg/kg) & $193.3 \pm 2.5^{\mathrm{b}}$ & $182.3 \pm 1.9^{\mathrm{c}}$ & $174.3 \pm 1.9^{\mathrm{b}}$ & $155.3 \pm 1.4$ & $129.3 \pm 1.1$ \\
\hline $\mathrm{D}($ distilled water $)$ & $132.5 \pm 1.0^{\mathrm{a}, \mathrm{b}}$ & $133.0 \pm 0.8^{\mathrm{a}, \mathrm{b}, \mathrm{c}}$ & $132.5 \pm 0.3^{\mathrm{a}, \mathrm{b}}$ & $130.0 \pm 0.4$ & $130.5 \pm 0.5$ \\
\hline
\end{tabular}

Means with the same superscript down the columns are significantly different at $\mathrm{P}<0.05$.

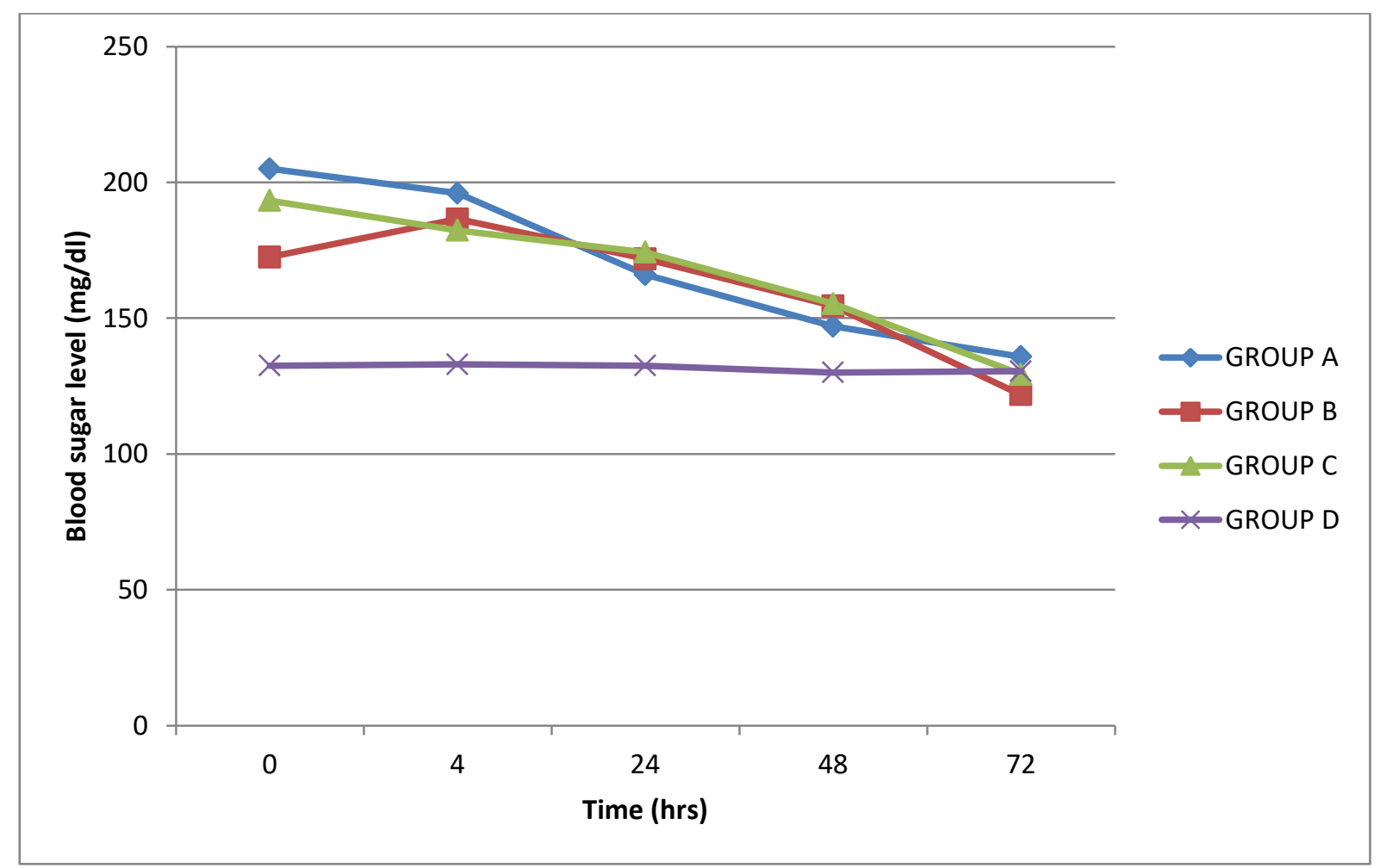

Figure1: Effect of treatments on sugar level of rabbits after inducing diabetes with alloxan 


\section{DISCUSSION}

The extract did not crash down the sugar level below normal following the use of the extract as seen after an initial use of glibenclamide. The difference in pattern of bringing down the sugar level as shown in Figure 1, indicated that group A (200mg/kg body weight) had a smooth response in lowering the sugar than the group $\mathrm{B}(250 \mathrm{mg} / \mathrm{kg}$ body weight). This is in line with the finding of Islam and Choi, (2007) where they reported green tea to have a dose response effect on hyperglycemia. In a study we conducted, high amount of flavonoids were present in methanolic extract of Momordica balsamina (Idris et al.,2018). Flavonoids have been reported to cause proliferation of pancreatic $\beta$-cells leading to increased secretion of insulin as the mechanism by which they reduce hyperglycemia caused by streptozotocin in diabetic rats (Mahesh and Menon, 2004; Sri- Balasubashini et al., 2004). The extract could possibly be acting by initial rapid release of insulin which is also a known property of glibenclamide that acts through inhibition of ATP-sensitive K+ channels (Candasamy, et al., 2014). It will be important to isolate the active principle (s) of this abundantly available indigenous medicinal plant. Hypoglycemic effect of Momordica balsamina, could also be due to the presence both phenols and flavonoids which serve as antioxidants to prevent toxic effects on tissue as well as some bioactive substance in the plant extract which have hypoglycemic potentials. Hence, it may play a significant role in the management of diabetes. However, there was no significant difference between any of the treated groups and the positive control which is a good indication of positive diabetic control. It is worthy of note that the group that received the higher dose had an initial average increase in blood glucose level before beginning to decline. Further study is required to find out responsible mechanism behind this action. The Momordica balsamina showed a significant therapeutic role in treatment of diabetes induced with alloxan. This may have important clinical use in management of diabetes in humans and animals.From this study, it may be concluded that methanolic extract of Momordica balsamina caused a reduction in blood glucose levels at 200 and $250 \mathrm{mg} / \mathrm{kg}$ body weight. These results suggest that the active principle (s) responsible for the hypoglycemic action may be due to stimulation of insulin release from pancreatic $\beta$-cells in alloxan-induced diabetic rabbits with a direct insulin-like action. Although the plant extract seems to be beneficial in hyperglycemic situations the toxicity can be further assessed using a chronic toxicity study to ensure safety in the use of this plant to manage diabetes and also to establish the mechanism of this action.

\section{CONCLUSION}

The methanolic extract of Momordica balsamina caused a reduction in blood glucose levels at 200 and $250 \mathrm{mg} / \mathrm{kg}$ body weight. This may have an important application in management of diabetes in humans and animals. Although the plant extract seems to be beneficial in hyperglycaemic situations the toxicity can be further assessed using chronic toxicity study to ensure safety in the use of this plant to manage diabetes and also to establish the mechanism of this action.

\section{REFERENCES}

Akinniyi, J.A., Sultanbawa, M.U.A. and Manawaku, D. (1986): The state of medicinal plant research in Nigeria. University Press lbadan Nigeria; 154-165

Benoit-Vical, F., Grellier, P., Abdoulaye, A., Moussa, I., Ousmane, A., Berry, A., Ikhiri, K. and Poupat, C. (2006): In vitro and in vivo antiplasmodial activity of Momordica balsaminaalone or in a traditional mixture. Chemotherapy 52: 288-292

Bot, Y.S., Mgbojikwe, L.O., Nwosu, C., Ambiku, A., Dadik, J. and Damshak, D (2007): Screening of the fruit pulp extract of Momordica balsaminafor anti HIV property. Afr. J. Biotechnol. 6: 47-52

Candasamy, M., Gopala, T. E., Murthy, K., Gubiyappa, K. S., Chellappan, D. K. and Gupta, G. (2014): Journal of Basic and Clinical Pharmacy.5, (3)

Dong, J.E., Ma, X.H., Wei, Q., Peng, S.B., and Zhang, S.C. (2011): Effects of growing location on the contents of secondary metabolites in the leaves of four selected superior clones of Eucommiaulmoides. Ind Crop Prod 34, 1607-1614.

Etuk, E.U. (2010): Animals models for studying diabetes mellitus. Agriculture and Biology Journal of North America 
Faujdar, S., Gauttam , V., and Kali, A.N.(2012): Antidiabetic potential of balsamina momordica L. Fruit pulp and its extracts in streptozocin induced diabetic wistar rats. International Journal of Ayurvedic and Herbal Medicine 2, (5)

Hassan, L.G and Umar, K.J (2006): Nutritional value of Balsam Apple (Momordica balsamina L.) Leaves. Pak. J. Nutr. 5, 522529

Islam, M.S. and Choi, H. (2007): Green Tea antidiabetic or diabetogenic: a dose response study. Pub med. US National library of medicine.National institute of Health.

Karumi, Y. and Bobboi, A. (1999): Hypoglycemic effects of Balsam Apple (momordica balsamina Linn) in Alloxan diabetic male rabbits. Biochemistry9, 795-808

Karumi, Y., Geidam, M.A. and Shettima, Y. (1999): Hypoglycemic properties of Momordica balsamina Linn fruits could be due to inhibition of glucose uptake in gastro-intestinal tract. West Afr. J. Biol. Sci.10, 84-91.

Karumi, Y., Onyeyili, P. and Ogugbuaja, V.O. (2003): Anti- inflammatory and antinociceptive (analgesic) properties of Momordica balsamina L. (Balsam apple) leaves in rabbits. Pak. J. Biol. Sci. 6, (17): 1515-1518

Konstantinos, P., Maciej, B., Michael, E., Nikolaos, P., and Dimitrios, P.(2015): Complications of Diabetes.Journal of Diabetes Research. (5) 189525

Mahesh, T. and Menon, P.V. (2004): Quercetin alleviates oxidative stress in streptozotocin induced diabetic rats. Phytother. Res.18, 123-127

Matawalli, A.G., Pakmam, I. and Laminu, H. (2004): Effect of aqueous stem bark extract of Momordica balsaminaLinn on serum electrolytes. Pak. J. Biol. Sci. 7, (8): 1430-1432

Michael, V.F and Anthony, J.A (2007): Proximate and mineral composition of the leaves of Momordica balsamina L.: an underutilized wild vegetable in Bostwana. Int. J. Food Sci. Nutr. 58: 419-423

Organization for Economic Development, Guidelines for the Testing of Chemicals (2006): Guidance no 425.Up and Down Procedure

Ponnusamy, S., Ravindran, R., Zinjarde, S., Bhargava, S. and Kumar, A.R. (2011): Evaluation of traditional Indian antidiabetic medicinal plants for human pancreatic amylase inhibitory effect in vitro. Evid Based Complement Alternat Med11: 515647.

Sasidharan, S., Chen, Y., Saravanan, D., Sundram, K. M., and Yoga Latha, L. (2011): Extraction, Isolation and Characterization of Bioactive Compounds from Plants' Extracts. African Journal of Traditional, Complementary, and Alternative Medicines 8, (1): $1-10$

Saxena, A. and Vikram, N.K. Role of selected Indian plants in management of type 2 diabetes (2004): A review. Journal of Alternative Complement Med 10, (2): 369-378.

Idris, S. B., Aminatu, A. S and Salihu, S. B. (2018): Phytochemical and Antioxidant Properties of Momordica balsamina .Vom Journal of Veterinary Science 13, $71-75$

Morgan L. (2017) Challenges and Opportunities in Managing Type 2 Diabetes. American health \& drug benefits, 10(4) 197-200

Sri Balasubashini, M., Rukkumani, R., Viswanathan, P. and Menon, P.V. (2004): Ferulic acid alleviates lipid peroxidation in diabetic rats. Phytother. Res.18, 310-314.

Tommas, I, D.N., Simone, F.D., Piacente, S., Pizza,C. and Mahmmod, N. (1995) Diterpenes from Momordica balsamina. Nat. Prod.Res. 6, (4): 261-268.

Yadav, S.V.V., Dhunnoo,Y. and Grover, J.K.(2002): Hypoglycemic and antihyperglycemic activity of Murrayakoenigii leaves in diabetic rats. Journal of Ethnopharmacology.82, (2-3), 111-116

Candasamy M., Murthy T.E.G.K., Gubiyappa, K.S., Chellappan, D.K., Gupta G.(2014) Alteration of glucose lowering effect of glibenclamide on single and multiple treatments with fenofibrate in experimental rats and rabbit models. Journal of Basic and clinical Pharmacy 5(3) 
